\title{
Very premature pubarche in girls is not a pubertal variant
}

\author{
Françoise Paris*, ${ }^{1}$ Nicolas Kalfa*, ${ }^{1,2}$ Pascal Philibert, ${ }^{1}$ Claire Jeandel, ${ }^{1}$ Laura Gaspari, ${ }^{1}$ \\ Charles Sultan ${ }^{1}$
}

${ }^{1}$ Unité d'Endocrinologie-Gynécologie Pédiatrique, Service de Pédiatrie 1, Hôpital Arnaud-de-Villeneuve, and Departement d'Hormonologie du Développement et de la Reproduction, Hôpital Lapeyronie, CHU Montpellier, et Université Montpellier 1, ${ }^{2}$ Service de Chirurgie Viscérale et Urologie Pédiatrique, Hôpital Lapeyronie, CHU Montpellier et Université Montpellier 1, France

* The authors contributed equally to this work

\begin{abstract}
Premature pubarche (PP) in girls is considered to be a benign phenomenon and is the clinical expression of premature adrenarche. Since it does not usually increase the risk of either abnormalities in pubertal development or a reduced final adult height, a non-interventional approach is generally adopted after exclusion of non-classical (NC) congenital adrenal hyperplasia (CAH). Extremely premature pubarche is nevertheless not a pubertal variant. We here report two cases of adrenocortical tumors (ACT) for which precocious pubarche was the initial sign. This report suggests that premature pubarche is not always a mere pubertal variant and that a delay in the etiological diagnosis can be harmful. Therefore, pubarche before the age of four years should be considered as a feature of ACT or NC CAH until proven otherwise.
\end{abstract}

Key words: Adrenarche, Adrenortical carcinoma, Puberty

\section{INTRODUCTION}

Premature pubarche (PP) in girls is commonly defined as the appearance of pubic hair before eight years of age. The pubic hair is generally limited to the labia majora and thus it may not be noted on casual examination. A larger area can be involved, however, leading parents to consult pediatric endo-

Address for correspondence:

Pr Charles Sultan, Unité d'Endocrinologie-Gynécologie Pédiatriques, Service de Pédiatrie 1, Hôpital Arnaud de Villeneuve, CHU Montpellier, 34295 Montpellier, France, Tel.: 334673386 96, Fax: 33467048573 ,

E-mail: c-sultan@chu-montpellier.fr

Received 27-12-11, Revised 25-01-12, Accepted 22-02-12 crinologists. The clinical presentation may include axillary hair and adult apocrine secretion, advanced bone maturation, and increased growth velocity, but pubic hair remains the most frequent symptom. The pathophysiological basis of premature pubarche is an early isolated maturation of the reticular zone of the adrenal gland with increased adrenal androgen secretion for chronological age (CA). The mechanism of the premature activation of the reticular zone remains unclear. ${ }^{1}$ Nevertheless, a high percentage of cases with heterozygocity of CYP21A2 has been reported $^{2,3}$ in isolated PP.

Premature pubarche is often considered a normal variant of puberty requiring nothing but an observa- 
tional approach. The non-interventional approach is supported by the observation that girls with premature gonadarche do not have early pubarche. All pubertal events seem to occur normally in girls with PP and target adult height is not modified ${ }^{4}$ even though metabolic syndrome and PCOS may develop, as recently noted in several reviews. ${ }^{1,5}$

Although these data appear reassuring, PP should nonetheless not be underestimated and remain unexplored, especially in the youngest patients. Besides the risk of undiagnosed congenital adrenal hyperplasia and later polycystic ovary syndrome in these patients, ${ }^{1}$ a more threatening pathology should be looked for because of the risk of an underlying malignancy. We here report two cases of adrenocortical tumors initially manifested with PP in early infancy.

\section{CASE REPORTS}

Between January 1990 and January 2010, an average of 30 girls per year were evaluated in our department for isolated premature pubarche. We recently focused on 36 of them who had been referred to our pediatric endocrinology clinic for PP between 2008 and 2009. Among these girls, $8.3 \%$ had non-classical adrenal hyperplasia and $22 \%$ had a heterozygote status; ${ }^{22}$ in the other cases, an ACTH stimulation test ruled out a defect in adrenal steroidigeneis and the final diagnosis was a benign condition related to early activation of the reticular zone. Nevertheless, among all the patients seen for PP between 1990 and 2010, two cases, observed in particularly young patients, were due to adrenocortical tumor (Table 1).

\section{Case 1}

A 23-month-old girl was presented with rapid development of pubic hair (P3 according to Tanner stage) and mild facial acne. Clinical inspection revealed a moderate increase in clitoral size, while palpation did not detect any abdominal mass. The initial abdominal ultrasonography was normal. Plasma testosterone was elevated $(2.6 \mathrm{nmol} / 1$, normal range for age $<1 \mathrm{nmol} / \mathrm{l})$. Plasma 17-OH-progesterone was $11.5 \mathrm{nmol} / \mathrm{l}$ (normal range for age $<3 \mathrm{nmol} / \mathrm{l}$ ), 11 desoxycortisol was $8.1 \mathrm{nmol} / \mathrm{l}$ (normal range for age $<7 \mathrm{nmol} / \mathrm{l}$ ), plasma DHEAS was $7.2 \mu \mathrm{mol} / \mathrm{l}$ (normal range for age $<2 \mu \mathrm{mol} / \mathrm{l})$, delta 4 androstenedione was $5 \mathrm{nmol} / 1$ (normal range for age $<6 \mathrm{nmol} / \mathrm{l}$ ), ACTH was $11.6 \mathrm{pmol} / \mathrm{l}$ (normal range for age $<12 \mathrm{pmol} / \mathrm{l}$ ), and cortisol was $410 \mathrm{nmol} / \mathrm{l}$ (normal range for age $<600 \mathrm{nmol} / \mathrm{l}$ ). The dexamethasone suppression test showed normal cortisol suppression. The bone age (BA) was advanced (4 years), weight was increased $(+3 \mathrm{SD})$, and growth velocity was accelerated $(+4 \mathrm{SD})$.

Table 1. Clinical findings, hormonal data, and follow-up for cases 1 and 2

\begin{tabular}{lll}
\hline & Case 1 & Case 2 \\
\hline Age (years) & 2 & 3 \\
Tanner staging & B1 P3 & B1 P3 \\
Associated initial symptoms & Clitoromegaly, & Clitoromegaly, \\
& mild facial acne & mild facial acne, and plethora \\
Bone age (years) & 4 & 3 \\
Weight and height (SDS) & $+4+4$ & Normal for age \\
Follow-up & Worsening of virilization (hirsutism, & Cushing syndrome \\
Plasma hormonal steroids & deepened voice), hepatic metastases & \\
& DHEAS: $7.2 \mu$ mol/l & DHEAS: $6.4 \mu m o l / 1(\mathrm{~N}<2 \mu \mathrm{mol} / \mathrm{l})$ \\
Abdominal US and CT scan & Testosterone: 6.97 nmol/1 & Testosterone: $10.7 \mathrm{nmol} / \mathrm{l}(\mathrm{N}<1 \mathrm{nmol} / \mathrm{l})$ \\
Treatment & Initially considered as normal & Adrenocortical mass: $40 \mathrm{~mm}$ \\
Follow-up & - Adjuvant chemotherapy (mitotane) & - Adrenalectomy
\end{tabular}

US: ultrasonography; CT: computed tomography 
Initial imaging, including cerebral and abdominal CT scans, was considered to be normal. The diagnosis at that time was a partial defect in 11 beta-hydroxylase.

After a transient improvement with hydrocortisone treatment, virilization progressively worsened with increasing clitoromegaly, deepened voice and hirsutism at the age of three years. The plasma testosterone rose to $6.97 \mathrm{nmol} / 1$ (normal range for age $<1 \mathrm{nmol} / \mathrm{l}$ ) and the advance in bone age increased further $(\mathrm{BA}=6$ years $/ \mathrm{CA}=3$ years $)$. A new hormonal and ultrasonographic assessment was performed. The final diagnosis was a metastatic adrenocortical tumor with hepatic involvement. The delay between the initial isolated pubarche and the definitive diagnosis was 13 months. Adjuvant chemotherapy with mitotane (OP'DDD) allowed radical surgery on both the adrenal gland and the liver (right hepatectomy). The pubarche regressed completely one month after surgery. The patient is still alive without recurrence after 20 years of follow-up.

\section{Case 2}

A three-year-old girl presented with a rapid development of pubic hair (Tanner stage P3) facial plethora and acne. Clinical examination revealed slight clitoromegaly. Bone age, height, and weight were normal for chronological age. No abdominal mass was palpable. Hyperandrogenism was confirmed by elevated plasma testosterone $(10.7 \mathrm{nmol} / \mathrm{l}$, normal range for age $<1 \mathrm{nmol} / \mathrm{l})$, DHEAS $(6.4 \mu \mathrm{mol} / \mathrm{l}$, normal range for age $<2 \mu \mathrm{mol} / \mathrm{l})$, and delta 4 androstenedione $(3.5 \mathrm{nmol} / \mathrm{l}$, normal range for age $<6 \mathrm{nmol} / \mathrm{l})$. The $17 \mathrm{OH}$ progesterone was also increased $(13.5 \mathrm{nmol} / \mathrm{l}$, normal range for age $<3 \mathrm{nmol} / \mathrm{l})$.

Premature pubarche was not associated with other pubertal signs. However, hypercortisolism and hyperaldosteronism were detected, presenting a picture compatible with Cushing syndrome. The low ACTH level (5.7 pmol/l, normal for age $<12 \mathrm{pmol} / \mathrm{l})$ and the high cortisol ( $735 \mathrm{nmol} / \mathrm{l}$, normal range for age $<600$ $\mathrm{nmol} / \mathrm{l}$ ) confirmed the adrenal origin of the hormonal abnormalities. A right adrenocortical mass of 40 mm was discovered by abdominal ultrasonography. The dexamethasone suppression test was thus not performed. There was no tumoral extension outside the adrenal. After exclusion of pheochromocytoma by meta-iodo-benzyl-guanidine (MIBG) scintigraphy, an adrenalectomy was performed. Histopathological examination confirmed a 5-cm adrenocortical tumor without extracapular extension or vascular invasion. The Weiss score was 4 . This was followed by regression of pubarche in the subsequent two months. The clitoromegaly persisted for six months with slow regression. No tumoral recurrence was observed after six years.

\section{DISCUSSION}

Premature pubarche is the clinical expression of premature adrenarche and is considered a benign phenomenon. ${ }^{6}$ This symptom progresses slowly and may be accompanied by moderate acceleration in growth and bone maturation without virilization. There is however little effect on the onset and progression of gonadarche or on the target adult height. ${ }^{4}$ Isolated premature pubarche in girls is often considered a normal pubertal variant, since it is secondary to an early isolated activation of the reticular zone, independent of gonadotropins. ${ }^{7}$ Several pathophysiological mechanisms of this precocious activation have been proposed: 1 enzymatic dysregulation of $\mathrm{P} 450 \mathrm{C} 17,{ }^{8}$ premature and rapid development of the zona reticularis, ${ }^{9}$ overweight or sudden weight gain, ${ }^{10}$ and hyperinsulinism. ${ }^{11}$

The increase in growth velocity and the advancement in bone age most often do not continue, so that puberty develops normally. These reassuring data support a non-interventional approach to isolated premature pubarche after exclusion of specific etiologies like congenital adrenal hyperplasia or adrenal adenoma.

Premature pubarche is nevertheless not always just a pubertal variant and a particularly young age of occurrence should raise the suspicion of a more threatening condition (Table 2). In the two cases we here describe, early pubarche was the initial sign of adrenocortical tumors (ACT). Malignancy revealed exclusively by androgen secretion-related symptoms is extremely rare. ${ }^{12}$ Many virilizing tumors, such as ACT, produce one type of hormone. It may, however, secrete various hormones, as in case 2 . Thus, Cushing's syndrome or high mineralocorticoid activity with hypertension are frequent manifestations of such tumors. ${ }^{13}$ 
Table 2. Differential diagnosis between premature adrenarche, late onset congenital adrenal hyperplasia, and adrenocortical tumor

\begin{tabular}{llll}
\hline & Idiopathic premature adrenarche & $\begin{array}{l}\text { Late onset congenital } \\
\text { adrenal hyperplasia }\end{array}$ & Adrenocortical tumor \\
\hline $\begin{array}{l}\text { Intrauterine growth } \\
\text { retardation }\end{array}$ & Frequent & No & No \\
Age & $<8$ years by definition & Prepubertal & $<4$ years is highly suspect \\
Clitoromegaly & Absent & Absent & Frequent and marked \\
Evolution & Slow progression & Slow progression & Explosive (in weeks) \\
Hypertension & Rare & Rare & Frequent \\
Other endocrine symptoms & NO & NO & Cushingoid syndrome frequent \\
Bone age & Conform or moderately advanced & Conform or moderately & Markedly advanced \\
& & advanced & Markedly elevated of all \\
Plasma androgens level & In normal range or slightly elevated & Increased basal or post & androgens precursors \\
& & synacthen 17OHP level & and \\
& & & $\begin{array}{l}\text { Frequent hypercortisolism and } \\
\text { hyperaldosteronism }\end{array}$ \\
Abdominal ultrasonography & Normal & & Adrenal mass
\end{tabular}

Premature pubarche as the revealing symptom of ACT is not the only clinical trap. The increased somatic growth of these children, their generally healthy appearance, and the lack of a palpable abdominal mass may divert pediatricians from considering the possibility of a malignant process. The resulting delay in diagnosis can be long and harmful, as in one of our cases. The prognosis for ACT is generally grim. MacFarlane ${ }^{14}$ reported that patients with untreated ACT have a median survival of only three months. In treated ACT, the overall five-year survival has ranged between $23 \%$ and $60 \%$ in different series. ${ }^{15}$ There is some evidence that earlier diagnosis and improved surgical management have both led to significantly better outcomes.

Both clinical and biological data can contribute to an early diagnosis. Even if the overall clinical examination cannot reliably distinguish between patients with a premature adrenarche and those with an ACT, four clues should raise the suspicion of an adrenal malignancy: (1) the explosive appearance of pubic hair, (2) clitoromegaly, (3) very early onset of pubarche (before the age of four years, which is rare in cases of isolated premature adrenarche), and (4) very advanced bone age. $\left({ }^{16}\right.$ Hypertension is also frequently encountered, as well as Cushingoid features. In such cases, hormonal evaluation, espe- cially plasma levels of DHEAS and testosterone, provide useful information, ${ }^{17}$ and particularly high values, as reported in case 1 . In isolated premature adrenarche, adrenal androgens can be increased for the chronological age but usually fall within the reference ranges for the $\mathrm{BA}$ and pubertal stage of pubic hair. ${ }^{18}$ In premature adrenarche, the adrenal androgens are also suppressed following dexamethasone testing, contrary to observations in patients with ACT. Atypical biological findings can nevertheless be misleading: (1) a transient antitumoral effect of dexamethasone, as described in case 1 , can lower the level of adrenal androgen, this followed by a marked secondary increase in androgens; and (2) adrenocortical tumors may show considerable biochemical heterogeneity and the steroid excretion pattern may change spontaneously..$^{19}$ Thus, in cases of prepubertal hyperandrogenism presenting particular diagnostic difficulty, abdominal CT-scan or preferably MRI should help make a definitive diagnosis. ${ }^{20}$

Although most androgen-secreting adrenocortical masses in children are benign, size, weight, and early occurrence are correlated with the malignant potential of these virilizing tumors ${ }^{21}$ and are chracterized by the frequent association of Cushingoid and androgenic features. Early diagnosis is mandatory, even in cases where isolated pubarche is the presenting symptom. 
Hence, we advise that pubarche in children under four years of age be considered as a feature of ACT until proven otherwise.

\section{REFERENCES}

1. Idkowiak J, Lavery GG, Dhir V, et al, 2011 Premature adrenarche: novel lessons from early onset androgen excess. Eur J Endocrinol 165: 189-207.

2. Dacou-Voutetakis C, Dracopoulou M, 1999 High incidence of molecular defects of the CYP21 gene in patients with premature adrenarche. J Clin Endocrinol Metab 84:1570-1574.

3. Witchel SF, Smith R, Tomboc M, Aston CE, 2001 Candidate gene analysis in premature pubarche and adolescent hyperandrogenism. Fertil Steril 75: 724-730.

4. Ibanez L, Virdis R, Potau N, et al, 1992 Natural history of premature pubarche: an auxological study. J Clin Endocrinol Metab 74: 254-257.

5. Oberfield SE, Sopher AB, Gerken AT, 2011 Approach to the girl with early onset of pubic hair. J Clin Endocrinol Metab 96: 1610-1622.

6. Saenger P, Reiter EO, 1992 Premature adrenarche: a normal variant of puberty? J Clin Endocrinol Metab 74: 236-238.

7. Counts DR, Pescovitz OH, Barnes KM, et al, 1987 Dissociation of adrenarche and gonadarche in precocious puberty and in isolated hypogonadotropic hypogonadism. J Clin Endocrinol Metab 64: 1174-1178.

8. Zhang LH, Rodriguez H, Ohno S, Miller WL, 1995 Serine phosphorylation of human $\mathrm{P} 450 \mathrm{c} 17$ increases 17,20-lyase activity: implications for adrenarche and the polycystic ovary syndrome. Proc Natl Acad Sci U S A 92: 10619-10623.

9. Palmert MR, Hayden DL, Mansfield MJ, et al, 2001 The longitudinal study of adrenal maturation during gonadal suppression: evidence that adrenarche is a gradual process. J Clin Endocrinol Metab 86: 4536-4542.

10. Jabbar M, Pugliese M, Fort P, Recker B, Lifshitz F, 1991 Excess weight and precocious pubarche in children: alterations of the adrenocortical hormones. J Am Coll Nutr 10: 289-296.

11. Rosenfield RL, 1996 Evidence that idiopathic functional adrenal hyperandrogenism is caused by dysregulation of adrenal steroidogenesis and that hyperinsulinemia may be involved. J Clin Endocrinol Metab 81: 878-880.

12. Cordera F, Grant C, van Heerden J, Thompson G, Young W, 2003 Androgen-secreting adrenal tumors. Surgery 134:874-880.

13. Icard P, Goudet P, Charpenay C, et al, 2001 Adrenocortical carcinomas: surgical trends and results of a 253-patient series from the French Association of Endocrine Surgeons study group. World J Surg 25: 891-897.

14. Macfarlane DA, 1958 Cancer of the adrenal cortex; the natural history, prognosis and treatment in a study of fifty-five cases. Ann R Coll Surg Engl 23: 155-186.

15. Vassilopoulou-Sellin R, Schultz PN, 2001 Adrenocortical carcinoma. Clinical outcome at the end of the 20th century. Cancer 92: 1113-1121.

16. Street ME, Weber A, Camacho-Hubner C, et al, 1997 Girls with virilisation in childhood: a diagnostic protocol for investigation. J Clin Pathol 50: 379-383.

17. Allolio B, Hahner S, Weismann D, Fassnacht M, 2004 Management of adrenocortical carcinoma. Clin Endocrinol (Oxf) 60: 273-287.

18. Voutilainen R, Perheentupa J, Apter D ,1983 Benign premature adrenarche: clinical features and serum steroid levels. Acta Paediatr Scand 72: 707-711.

19. Halmi KA, Lascari AD 1971 Conversion of virilization to feminization in a young girl with adrenal cortical carcinoma. Cancer 27:931-935

20. Bonfig W, Bittmann I, Bechtold S, et al, 2003 Virilising adrenocortical tumours in children. Eur J Pediatr 162: 623-628.

21. Wolthers OD, Cameron FJ, Scheimberg I, et al, 1999 Androgen secreting adrenocortical tumours. Arch Dis Child 80: 46-50.

22. Paris F, Tardy V, Chalancon A, Picot MC, Morel Y, Sultan C, 2010 Premature pubarche in Mediterranean girls: high prevalence of heterozygous CYP21 mutation carriers. Gynecol Endocrinol 26: 319-324. 